Article

\title{
Agglomeration, Structural Embeddedness, and Enterprises' Innovation Performance: An Empirical Study of Wuhan Biopharmaceutical Industrial Cluster Network
}

\author{
Jingjing Zeng ${ }^{1}$, Dingjie Liu ${ }^{1}$ and Hongtao $\mathrm{Yi}^{2,3, *}$ \\ 1 School of Public Administration, Zhongnan University of Economic and Law, Wuhan 430000, China \\ 2 School of Public Administration and Policy, Renmin University of China, Beijing 100872, China \\ 3 John Glenn College of Public Affairs, The Ohio State University, 1810 College Rd, Columbus, OH 43221, USA \\ * Correspondence: yihongtao@ruc.edu.cn
}

Received: 12 June 2019; Accepted: 9 July 2019; Published: 18 July 2019

\begin{abstract}
Industry cluster's agglomeration effects facilitate higher productivity for enterprises located in the industry cluster. This paper examines the agglomeration effects of industry cluster on firm's innovation performance through studying the network embeddedness of the biopharmaceutical companies using cross-sectional data from 2011 to 2015. Measuring the technological cooperation network with text analysis of the interfirm agreement among core enterprises, we found that betweenness centrality and clustering coefficient have statistically significant and positive effects on enterprise's ability for technological innovation, while the influence from the constraint of structural holes is negative. Our results suggest that government should allow the leading enterprises to establish professional technology cooperation platforms and provide additional support to promote cooperation among firms.
\end{abstract}

Keywords: industry cluster; agglomeration effects; structural embeddedness; innovation performance; biopharmaceutical industry

\section{Introduction}

Over the past several decades, economists have examined the critical role that industrial cluster plays in generating innovation performance by asking how and why industrial cluster could accelerate overall innovation performance within the cluster. Extant studies on this question have mainly focused on two aspects. The first stream of literature has focused on the industry cluster as an integrated object, and researchers following this tradition study competitive advantages of industry clustering. Porter has been one of the pioneers in studying the competitive edge of industry cluster at the national level [1]. It is increasingly popular to combine the theory of new economic geography with the development of industry cluster to study the effects of geographical proximity on regional economic output [2]. Another stream of research that investigates industry cluster's impacts on innovation performance is centered on the roles of enterprises within the industrial cluster. An increasing number of studies have paid attention to the agglomeration effect of enterprise's innovation performance at the micro-level [3,4]. Other studies have been conducted to examine the interaction between enterprises or even different actors within and beyond clusters [5-7]. The research on agglomeration effects of industry cluster and enterprises' innovation performance has generated an international literature and academic dialogue. In particular, it becomes highly relevant in China as China intensifies its industrial reconstructing. How to strengthen enterprises' innovation capability in an increasingly globalized and industrialized network remains one of the main tasks for firms and government in China. 
As a representative high-tech industry, the biopharmaceutical industry demonstrates features of agglomeration in technology and capital. Under the market economy with Chinese characteristics, biomedical industrial parks of different sizes have nurtured during the past ten years. Influenced by policy guidance and industry planning by local governments, biopharmaceutical industry has taken off rapidly. Examples include Zhangiiang Park of Shanghai and Optical Valley Park of Wuhan, both of which have begun to generate agglomeration effect. With more frequent joint technology R\&D and industry-university-research cooperation, biomedicine enterprises developed close and reciprocal cooperation relationships, through signing technological collaboration contracts between and among biomedicine enterprises, universities, and research institutions. Whether this microcontract cooperative mechanism has promoted innovation performance of biomedicine enterprises has significant practical implications for these enterprises. An equal and reciprocal cooperative contract will likely lead to quality cooperation, and induce more technology sharing and spatial agglomeration of enterprises. Therefore, we analyze whether the agglomeration effects of biomedicine industry have produced impacts on innovation performance. The practical implications of this study are to inform enterprises of the technological development patterns and to facilitate evidence-based policy making on science and technology policy.

This study presents a novel perspective to the study of local industrial cluster in the following ways. First, we collected unique network data on Wuhan Biopharmaceutical Industrial Cluster Network, which was one of the first in the literature to focus on industrial innovation in central China region. Second, we are able to predict corporate innovation performance with network indicators, as informed by social capital theories. This study helps build a bridge between social science theories and innovation research.

The next section focuses on the technological connections among the enterprises in the industry cluster network. Then we discuss inherent logic connections among market transactions, agglomeration effects and innovation performance, based on which we formulate hypotheses that agglomeration effect measured by structure embeddedness of the core enterprises would promote firms' technological innovation ability and economic performance. We then collect data from various sources, including websites of these enterprises, the Patent Star (China's official patent website) and CNKI (China National Knowledge Infrastructure). After coding these data, we run social network analysis to measure the scale of cluster's agglomeration effects. Then two empirical models are estimated to test the hypotheses and examine subnetwork structures. The results showed that betweenness centrality and clustering coefficient are positively related to enterprises' technological innovation capability, while structural holes produce negative impacts. We conclude with policy implications that professional platforms should be established by core enterprises, and that government should provide a supportive environment to promote close cooperation among enterprises.

\section{Literature Review}

With interdependent enterprises, science and research institutions, intermediary organizations and consumers, industry cluster takes the shape of a closely connected network, which leads to agglomeration effects [8]. Agglomeration effects of industry cluster presents a process of knowledge and information disseminating, human resource sharing, cooperative and compatible matchmaking among different enterprises. This leads to an external economy for enterprises to acquire higher productivity [9]. Enterprises' connection degree in industry cluster network can be measured by the degree of spillover in network resources and the strength of embeddedness in network structure.

The spillover of resources, including knowledge, information, personnel, capital, and technology in and between clusters, has become an emerging research topic $[10,11]$. Knowledge spillover was particularly emphasized by Powell [10] and Simona [12]. Knowledge connections were further divided into component knowledge and architectural knowledge to study their differentiated effects on cluster knowledge spillover and competitive edge [13]. Financial transaction network among film businesses in Potsdam, Germany was examined [14]. Formal and informal managerial connections between 
cluster enterprises were utilized to study the effects of Toronto mutual fund cluster network connections on enterprises' innovation performance [15]. It is argued that information advantage enjoyed by core enterprises enhances knowledge spillover in the cluster [16].

Recently, researchers started to evaluate cluster network's agglomeration degree through its structural embeddedness [17-19]. Qian took structural hole and centrality as two major indicators to measure the adjustment effects, while paying close attention to effects in economic output brought by enterprises' position in Shenzhen ICT cluster network [20]. Research on Chengdu furniture manufacturing in China showed that cluster network's structural embeddedness generated pronounced impacts on the enterprise's outputs, finding positive effects of degree centrality and betweenness centrality [19]. Another study on the textile industry cluster with economic performance demonstrated that science and technology research institutions and leading businesses play a key role in cluster network. At the same time, a good network position would enhance the innovation capability of an enterprise, facilitating multiple outputs [21]. Resource acquisition ability of enterprises in technological knowledge was taken into consideration to build a more comprehensive model in testing network centrality and intermediary effect on innovation improvement [22-25]. Further analysis investigated the impact of clustering coefficient on output efficiency of equipment manufacturing in Northeast China [26].

In this paper, we combine technological spillover with cluster's network structure embeddedness. The scale of agglomeration effects can be measured by the degree of network structural embeddedness, operationalized with the number of technological cooperation contracts and agreements among enterprises. At the same time, economic attributes and self-learning property are highlighted in our paper, while emphasis is placed on interactions among organizations in the cluster network [27].

\section{Theoretical Framework and Hypotheses}

Network structure is determined by enterprises' relative positions, the functions they possess, and the types of links between these enterprises and other actors. The features of network structure have significant impact on agglomeration, enhancing the firms' economic outputs.

\subsection{Agglomeration Effect of Industry Cluster}

Relationships existed in a cluster network can be used as a valuable resource [28] and innovative activities usually accompany efficient resource collection and accurate processing. Effective absorption and efficient use of external resources may give enterprise more opportunities to survive in intense market competition [29]. Through mechanisms to enhance trust-building, information exchange, and joint problem-solving, industry cluster regulates enterprises' market operation and expectations [30]. Market transactions, agglomeration effects and innovation performance are closely correlated, when firms are clustered in a network.

First of all, market transactions promote agglomeration effects within the industry cluster. After repeated market trading operations, each enterprise in the cluster network would observe the cooperation contracts and respect the interests of other firms. As a result, ad hoc cooperation or speculative trading is replaced by long-term cooperation based on mutual benefits [31,32]. The so-called "habitual" trust relationship becomes a credible commitment for each party. Any actions that break the contract will suffer immense loss in capital financing, information access and reputation, impeding further cooperation within the cluster. Over the long run, this will turn an enterprise into an active cooperator who prefers a collaborative strategy. Under the environment with high mutual trust, incidences to break the contract will drop, while transaction costs and fees paid by enterprises will be minimized.

Secondly, a spillover cluster environment is facilitated by agglomeration effects. A higher level of agglomeration effect means more frequent exchange of knowledge, information, capital, and personnel. All these will have great impacts on enterprises' innovation performance through network structural embeddedness [33]. General equilibrium model of moral hazard problem confronted by heterogeneous 
groups in market transaction demonstrated the sustainable growth effect in outputs brought by trustful environment $[34,35]$.

\subsection{Betweenness Centrality and Innovation Performance}

Betweenness centrality for individual enterprise refers to proportion of the shortest paths (or geodesics) that must be passed through, and it accounts for all the shortest paths in the cluster network. Active and efficient involvement in information transmission leads to a higher betweenness centrality score for an enterprise. An enterprise may enjoy a dominant position if it possesses multiple shortest information paths. The formula for betweenness centrality can be shown as [36]

$$
\text { betweenness centrality }{ }_{i t}=\sum_{j<k} g_{j k}\left(n_{i}\right) / g_{j k}
$$

of which $g_{j k}\left(n_{i}\right)$ means the number of the shortest paths passed through enterprise $i$ in all paths between enterprise $j$ and $k . g_{j k}$ represents the total number of paths between enterprise $j$ and $k$.

Hypothesis 1: Betweenness centrality of the enterprise is positively related to its level of technological innovation.

Hypothesis 2: Betweenness centrality of the enterprise is positively related to its economic performance.

\subsection{Structural Holes and Innovation Performance}

Structural holes will be developed if two adjacent market actors (both are indirectly connected through a third enterprise (i) are not directly connected. Heterogeneous connections are possessed by enterprise i who acts as a "bridge" that control diverse information exchange paths. This would provide enterprise i with an advantage in facilitating industrial application of their hi-tech research findings. However, for the two actors who have to connect with enterprise $i$ in the industry cluster, structural holes will likely constrain technological knowledge acquisition and other market activities. We focus on the aggregate constraint of structural hole on enterprise's innovation outputs. So the constraint degree of enterprise i affected by enterprise $\mathrm{j}$ can be demonstrated as [37]

$$
\mathrm{C}_{\mathrm{ij}}=\left(p_{\mathrm{ij}}+\sum_{\mathrm{q}} \mathrm{P}_{\mathrm{iq}} \mathrm{m}_{\mathrm{qj}}\right)^{2}
$$

$P_{i q}$ presents the proportion of the paths that will get through or is affected by enterprise $q$, accounting for the number of connections to enterprises within the cluster. $\mathrm{m}_{\mathrm{qj}}$ means the marginal strength of the connection from enterprise $j$ to enterprise $q$ or the value of the connection from enterprise $\mathrm{j}$ to enterprise $q$ plus the highest values in all the connections that are linked with enterprise $\mathrm{j}$. So the formula of enterprise $i$ in limitation degree can be described as

$$
\text { structural holes }_{i t}=\sum_{j} C_{i j}
$$

Huge cost will likely be incurred in maintaining a healthy relationship with enterprises or other market actors for a pharmaceutical enterprise. Under this condition, redundant links must be cut off and resources in management must be put into key connections to achieve efficient output both for the enterprise and the community. A higher structural hole constraint would result in a lower degree of freedom for the enterprise to seek opportunities for cooperation.

Hypothesis 3: Structural holes in the constraint are negatively related to an enterprise's technological innovation. 
Hypothesis 4: Structural holes in the constraint are negatively related to an enterprise's economic performance.

\subsection{Clustering Coefficient and Innovation Performance}

Clustering coefficient measures the quality or frequency of one enterprise's connection with its neighboring actors. The definition is [38]

$$
\mathrm{C}_{\mathrm{i}}=2 \mathrm{e}_{\mathrm{i}} / \mathrm{k}_{\mathrm{i}}\left(\mathrm{k}_{\mathrm{i}}-1\right)
$$

$C_{i}$ is the clustering coefficient of enterprise $i$, of which $k_{i}$ represents the degree centrality of enterprise $i$ and $e_{i}$ means the number of links between its cooperators. Further, $C_{t}$, the clustering coefficient of the cluster network can be defined as

$$
\text { clustering coefficients }_{t}=\left\lceil\sum_{i=1}^{N} C_{i}\right\rceil / N
$$

High quality links and frequent cooperation among enterprises located in a cluster network enhance their relationship, trust, and stability and improve efficiency in resource sharing, driving innovative activities.

Hypothesis 5: Clustering coefficient of an enterprise is positively related to its technological innovation.

Hypothesis 6: Clustering coefficient of an enterprise is positively related to its economic performance.

\section{Research Design}

\subsection{Network Boundary}

Establishing network boundary is key in applying social network analysis to industrial cluster study, the process of which includes defining the cluster boundary, cluster actor selection, and measurement of network links.

\subsubsection{Why Study Biopharmaceutical Industry Cluster in Wuhan}

With a comparative advantage in land, labor and transportation costs and favorable industrial policies, Wuhan has become an emerging city in biopharmaceutical industry. More than 500 enterprises have been established within six industry parks in Wuhan East Lake High-tech Zone, with a total corporate income over 500 billion RMB yuan, the third place in China. Since the year of 2008, cooperation between enterprises, universities and research institutions has become more frequent and agglomeration effects have emerged. Biopharmaceutical industry features high degree of agglomeration in capital and high-tech talents, and agglomeration effects of enterprise reflects cluster level environmental change.

\subsubsection{Defining Network Actors and Measuring Network Connections}

The roles the enterprises play are embedded in their network relationships in the cluster network. In this study, we focus on connections between core biopharmaceutical enterprises and other enterprises which show similar features with core enterprises, universities and research institutions. The network relationships capture both industry-university-research cooperation and interfirm cooperation within the Wuhan East Lake High-Tech Zone.

To measure the cluster network, we focus on technological cooperation that spans new technological innovation, patent application and product development. All these can be clearly measured by inter-enterprise contracts or agreements, which were collected by searching enterprises' websites, the Patent Star, China's official patent website and CNKI. Contracts or cooperative texts are available online, and numbers of cooperation and duration of such cooperation are coded. For example, if a 
contract or a cooperative agreement was signed between enterprises $i$ and $j$, then, we assume that an equal, reciprocal and undirected link was established between them.

\subsubsection{The Process of Identifying Core Enterprise Network}

As discussed above, technological cooperation data of a hundred and one biopharmaceutical enterprises within Wuhan East Lake High-Tech Zone were collected and coded based on technical cooperation contracts among these enterprises from 2011 to 2015. Then we conduct two rounds of interviews (one conducted in 2 June 2015 and another in 2 December 2015) with biopharmaceutical industry park leaders of Wuhan East Lake High-Tech Zone and senior managers of nine leading profitmaking enterprises, including chemical drug enterprises; traditional Chinese medicine enterprises; and biological product enterprises. The network data for forty core enterprises are collected from the interviews. With the interview data, we are able to capture the core network of the biopharmaceutical industry cluster. See Table 1 for descriptions of the number of links for the core enterprises.

Table 1. Numbers of links for the core enterprises.

\begin{tabular}{cccccccccccc}
\hline ID & NL & ID & NL & ID & NL & ID & NL & ID & NL & ID & NL \\
\hline C1 & 40 & C 8 & 7 & C15 & 8 & C22 & 11 & C29 & 4 & C36 & 9 \\
C2 & 21 & C9 & 7 & C16 & 9 & C23 & 7 & C30 & 11 & C37 & 11 \\
C3 & 38 & C10 & 7 & C17 & 12 & C24 & 6 & C31 & 4 & C38 & 2 \\
R4 & 16 & C11 & 4 & C18 & 26 & C25 & 8 & C32 & 2 & C39 & 3 \\
C5 & 10 & C12 & 15 & C19 & 11 & C26 & 3 & C33 & 5 & C40 & 6 \\
C6 & 8 & C13 & 6 & C20 & 25 & C27 & 8 & C34 & 4 & & \\
C7 & 12 & C14 & 2 & C21 & 18 & R28 & 45 & C35 & 6 & & \\
\hline \multicolumn{7}{c}{ Note: ID: ID of enterprises; NL: Number of Links. }
\end{tabular}

A visualization of the core enterprises in the industrial cluster was performed with Pajek4.0. Core enterprises are located in the center of structure graph, while universities, research institutions, and enterprises of the same type are distributed in the periphery, as show in Figure 1.

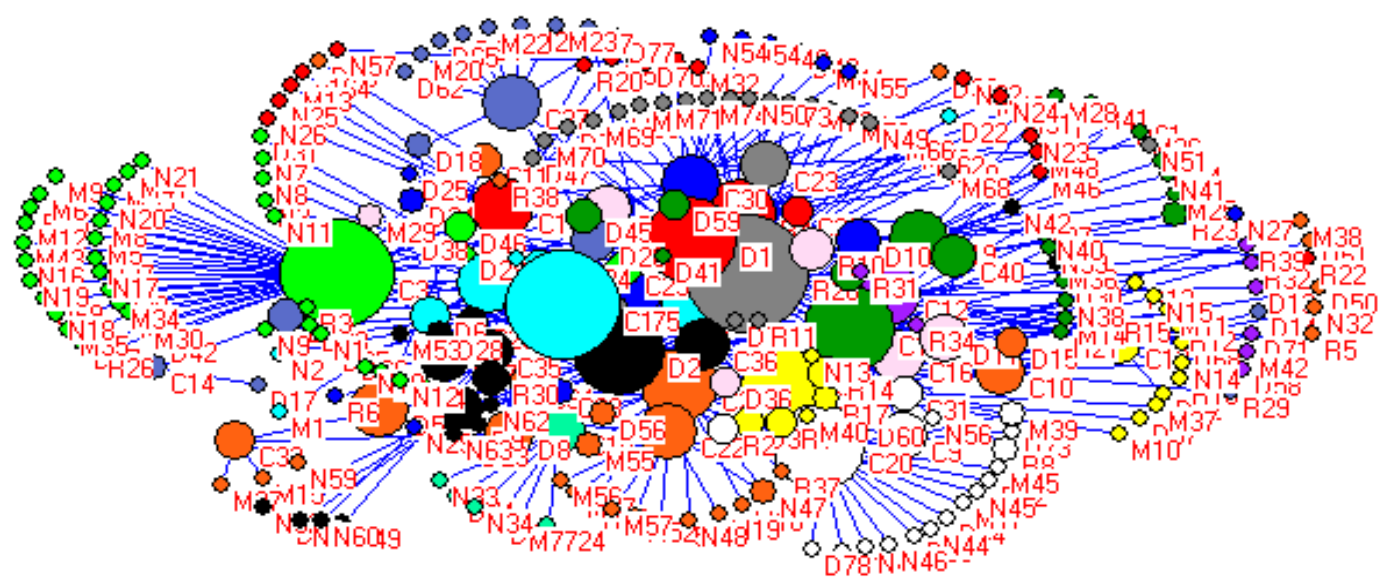

Figure 1. Cluster network structure of core enterprises (40).

\subsection{Variables}

\subsubsection{Research Method}

Betweenness centrality, constraint of structural holes and clustering coefficient of structure embeddedness in agglomeration effects are calculated with Pajek4.0. A linear regression model is employed to test the effect of structural embeddedness on its innovation performance. Firstly, only control variables are included in the regression model, then, explanatory variables are included to test 
their effects on patent outputs. Secondly, explanatory variables are added to test the effects on profits of new products from 2012 to 2015, separately.

\subsubsection{Description of Explanatory Variables}

Table 2 provides descriptive statistics for the explanatory variables used in this study.

Table 2. Description of explanatory variables in core cluster network.

\begin{tabular}{llllllll}
\hline ID & \multicolumn{1}{c}{ BC } & \multicolumn{1}{c}{ SH } & \multicolumn{1}{c}{ CC } & \multicolumn{1}{c}{ ID } & \multicolumn{1}{c}{ BC } & \multicolumn{1}{c}{ SH } & \multicolumn{1}{c}{ CC } \\
\hline C1 & 0.157617 & 0.035807 & 0.11626 & C21 & 0.093471 & 0.076411 & 0.022222 \\
C2 & 0.076787 & 0.053872 & 0.019858 & C22 & 0.04013 & 0.124327 & 0.010864 \\
C3 & 0.169376 & 0.028493 & 0.043678 & C23 & 0.024969 & 0.148234 & 0.002469 \\
R4 & 0.056544 & 0.071986 & 0.015715 & C24 & 0.012952 & 0.176842 & 0.002222 \\
C5 & 0.029577 & 0.10644 & 0.005817 & C25 & 0.0218 & 0.143745 & 0.004134 \\
C6 & 0.022385 & 0.126493 & 0.000961 & C26 & 0.001691 & 0.347779 & 0.000533 \\
C7 & 0.031276 & 0.122398 & 0.010816 & C27 & 0.020495 & 0.143745 & 0.003419 \\
C8 & 0.013175 & 0.166026 & 0.003509 & R28 & 0.215283 & 0.030901 & 0.140625 \\
C9 & 0.011427 & 0.165484 & 0.004159 & C29 & 0.000599 & 0.32136 & 0.002133 \\
C10 & 0.030958 & 0.161061 & 0.005761 & C30 & 0.039597 & 0.095454 & 0.00388 \\
C11 & 0.012777 & 0.25 & 0 & C31 & 0.008239 & 0.260417 & 0.000855 \\
C12 & 0.052635 & 0.080458 & 0.007133 & C32 & 0.006237 & 0.5 & 0 \\
C13 & 0.019409 & 0.166667 & 0.000002 & C33 & 0.018782 & 0.2 & 0 \\
C14 & 0.006237 & 0.5 & 0 & C34 & 0.003452 & 0.25 & 0 \\
C15 & 0.03727 & 0.125 & 0 & C35 & 0.016303 & 0.170278 & 0.00112 \\
C16 & 0.027626 & 0.111111 & 0 & C36 & 0.023234 & 0.125668 & 0.003846 \\
C17 & 0.044649 & 0.089968 & 0.007273 & C37 & 0.051374 & 0.090909 & 0.000003 \\
C18 & 0.08384 & 0.04622 & 0.031515 & C38 & 0.00016 & 0.5 & 0 \\
C19 & 0.041511 & 0.111118 & 0.006984 & C39 & 0.006237 & 0.357108 & 0.000855 \\
C20 & 0.084763 & 0.041662 & 0.009107 & C40 & 0.015736 & 0.166667 & 0.000002 \\
\hline
\end{tabular}

Note: ID: code of enterprises; BC: betweenness centrality; SH: constraint of structural holes; CC: clustering coefficient; All values were calculated with Pajek4.0.

\subsubsection{Dependent Variables}

Innovation performance outputs can be measured in different ways, with indicators on technological, financial, and management performance. We select patent output to evaluate innovation capability of enterprise based on previous studies. Patents authorized from 2011 to 2015 are archived and coded. R \& D investment, average annual profits in new products and net profits can be used to evaluate economic performance at the micro-level. Here we choose average annual profits in new products as our measure. All these profits data are collected through our interview with administrative staff in the biopharmaceutical industry park.

\subsubsection{Control Variables}

Capital investment in innovation and management has impacts on the outputs of new products. Capital investment represents comprehensive strengths and strategic management in development. Although biopharmaceutical industry possesses high degree of agglomeration in capital and high-tech talents, it takes a long period for technology development and patent application. Thus time capital also plays a key role in innovation. The registered capital assets and establishment of joint stock enterprise time span were taken into consideration as two control variables. See Table 3 for detailed information for all the variables. 
Table 3. Descriptive statistics.

\begin{tabular}{ccccc}
\hline VAR & Max & Min & Mean & N \\
\hline BC & 0.22 & 0.00 & 0.03 & 40 \\
SH & 0.5 & 0.03 & 0.17 & 40 \\
CC & 0.14 & 0 & 0.01 & 40 \\
Lnyp11 & 12.62 & 6.22 & 8.82 & 39 \\
Lnyp12 & 13.22 & 6.36 & 9.30 & 39 \\
Lnyp13 & 13.43 & 6.36 & 9.70 & 39 \\
Lnyp14 & 13.58 & 6.90 & 9.79 & 39 \\
Lnyp15 & 13.64 & 7.22 & 9.87 & 39 \\
Patents & 50 & 1 & 10.13 & 40 \\
RT & 22 & 3 & 10.28 & 39 \\
RC & 10.82 & 6.22 & 8.19 & 39
\end{tabular}

Note: Lnyp: annual profits from 2011-2015; P: patents; RT: registered time; RC: registered capital. Data were log-transformed.

\section{Empirical Analysis}

\subsection{Pearson Correlation Result}

Pearson correlation coefficient was calculated between explanatory variables and dependent variables. From the results, Pearson correlation values between betweenness centrality, constraint of structural holes, clustering coefficient and patent outputs are $0.828,-0.556$, and 0.795 , which are all statistically significant at the 0.01 level. Pearson correlation values between betweenness centrality, structural holes, clustering coefficient and economic performance from 2012 to 2015 are also very strong. The results are presented in Table 4.

Table 4. Pearson correlation result.

\begin{tabular}{|c|c|c|c|c|c|c|c|c|}
\hline $\begin{array}{l}\text { Control } \\
\text { Variables }\end{array}$ & & & $\mathbf{P}$ & Lnyp11 & Lnyp12 & Lnyp13 & Lnyp14 & Lnyp15 \\
\hline \multirow[t]{4}{*}{ RT \& RC } & $\mathrm{BC}$ & $\begin{array}{c}\text { Correlation } \\
p \text {-value }\end{array}$ & $\begin{array}{c}0.828 * * * \\
0.000\end{array}$ & $\begin{array}{c}-0.03 \\
0.86\end{array}$ & $\begin{array}{c}0.556^{* * *} \\
0.000\end{array}$ & $\begin{array}{c}0.736 \text { *** } \\
0.000\end{array}$ & $\begin{array}{c}0.761^{* * *} \\
0.000\end{array}$ & $\begin{array}{c}0.712 \text { *** } \\
0.000\end{array}$ \\
\hline & $\mathrm{SH}$ & $\begin{array}{c}\text { Correlation } \\
p \text {-value }\end{array}$ & $\begin{array}{c}-0.556^{* * *} \\
0.000\end{array}$ & $\begin{array}{c}-0.329 \\
0.047\end{array}$ & $\begin{array}{c}-0.587^{* * *} \\
0.000\end{array}$ & $\begin{array}{c}-0.667^{* * *} \\
0.000\end{array}$ & $\begin{array}{c}-0.767^{* * *} \\
0.000\end{array}$ & $\begin{array}{c}-0.713^{* * *} \\
0.000\end{array}$ \\
\hline & $\mathrm{CC}$ & Correlation & $0.795^{* * *}$ & 0.014 & 0.376 & $0.609 * * *$ & $0.628^{* * *}$ & $0.69 * * *$ \\
\hline & & $p$-value & 0.000 & 0.934 & 0.022 & 0.000 & 0.000 & 0.000 \\
\hline
\end{tabular}

Note: 2-tailed; ${ }^{* * *}$ : significant at 0.01 level.

\subsection{Testing the Hypotheses}

\subsubsection{OLS Regression Analysis}

We employ ordinary least square (OLS) regressions to test our hypotheses. We use OLS due the fact that our dependent variable is continuous and that our data is cross-sectional. Two empirical models are estimated to test the hypotheses:

Model 1: $P=\beta_{1}+\beta_{2} B C+\beta_{3} S H+\beta_{4} C C+\beta_{5} R T+\beta_{6} R C+\varepsilon$

Model 2: $\operatorname{Lnyp}_{(t)}=\beta_{1}+\beta_{2} B C+\beta_{3} S H+\beta_{4} C C+\beta_{5} R T+\beta_{6} R C+\varepsilon$

Four submodels are estimated with explanatory variables $\mathrm{BC}, \mathrm{SH}, \mathrm{CC}$ and control variables RT and RC based on model 1 with linear regression method.

Explanatory variables BC, BH and CC are included separately in submodels 2 to 4 based on submodel 1, which added additional control variables. Regression results show relatively large and positive coefficients for $\mathrm{BC}$ and $\mathrm{CC}$, which are 208.383 and 391.705, $\mathrm{F}(\mathrm{BC})=34.02, \mathrm{P}(\mathrm{BC})<0.01$; $\mathrm{F}(\mathrm{CC})=27.29, \mathrm{P}(\mathrm{CC})<0.01)$. Regression coefficient is negative and $\mathrm{F}(\mathrm{SH})=9.11, \mathrm{P}(\mathrm{SH})<0.01$ in $\mathrm{S}-\mathrm{M} 3$, which are also significant. A higher goodness-of-fit in Model 1 (Adj- $\mathrm{R}^{2}=0.77$ ) showed a better explanation for the effect of agglomeration effects on innovation capacity improvement. From 
all of the above, we can draw a conclusion that agglomeration effects have accelerated innovation capacity to some degree. Hypotheses 1, 3, and 5 have been supported. Table 5 reports results for the regression models.

Table 5. Regression analysis between structure embeddedness and patent outputs.

\begin{tabular}{|c|c|c|c|c|c|}
\hline VAR & Sub Model 1 & Sub Model 2 & Sub Model 3 & Sub Model 4 & Model 1 \\
\hline RT & $\begin{array}{c}0.809 \text { ** } \\
(2.3)\end{array}$ & $\begin{array}{c}0.419 * * \\
(2.05)\end{array}$ & $\begin{array}{c}0.697^{* *} \\
(2.34)\end{array}$ & $\begin{array}{c}0.245 \text { * } \\
(1.08)\end{array}$ & $\begin{array}{c}0.287 \text { * } \\
(1.49)\end{array}$ \\
\hline $\mathrm{RC}$ & $\begin{array}{l}0.689 \\
(0.75)\end{array}$ & $\begin{array}{l}-0.439 \\
(-0.81)\end{array}$ & $\begin{array}{l}0.241 \\
(0.31)\end{array}$ & $\begin{array}{c}-0.059 \\
(-0.1)\end{array}$ & $\begin{array}{l}-0.375 \\
(-0.76)\end{array}$ \\
\hline $\mathrm{BC}$ & & $\begin{array}{c}208.383^{* * *} \\
(8.74)\end{array}$ & & & $\begin{array}{c}95.7 * * \\
(2.18)\end{array}$ \\
\hline $\mathrm{SH}$ & & & $\begin{array}{c}-40.741^{* * *} \\
(-3.95)\end{array}$ & & $\begin{array}{c}-12.32^{* *} \\
(-1.47)\end{array}$ \\
\hline $\mathrm{CC}$ & & & & $\begin{array}{c}391.705^{* * *} \\
(7.74)\end{array}$ & $\begin{array}{c}215.06^{* * *} \\
(2.99)\end{array}$ \\
\hline $\mathrm{N}$ & 39 & 39 & 39 & 39 & 39 \\
\hline F & $4.15^{* * *}$ & $34.02 * * *$ & $9.11^{* * *}$ & $27.29 * * *$ & $26.55^{* * *}$ \\
\hline $\operatorname{Adj}-R^{2}$ & 0.14 & 0.72 & 0.39 & 0.67 & 0.77 \\
\hline
\end{tabular}

Regression analysis of explanatory variables on innovation capacity tests whether stronger ability in technological knowledge learning and information processing has been developed in the cluster network. We study whether technological knowledge acquisition and processing have been applied in industrialization, and whether they have improved economic performance.

Regression results of S-M 5 to 7 showed BC and CC didn't promote profits of enterprise and constraint of SH has negative relationship with profit achievement. Negative regression coefficient of constraint of SH is present in 2012 to 2015, of which $p(2012)<0.05, p(2013)<0.05, p(2014)<0.01$, $p(2015)<0.05$, which is also statistically significant. These results are supportive for hypothesis 4 , but not for hypotheses 2 and 6.

\subsubsection{Multicollinearity Test}

After testing our hypotheses, we have conducted multicollinearity test with STATA 13. The results showed that VIF values for all explanatory variables are less than 10 and the average VIF value is 3.64. The VIF value for BC, SH, CC, RT, RC is 7.48, 1.9, 6.09, 1.29, and 1.43. Thus we can conclude that we do not observe serious multicollinearity among the independent variables.

\subsubsection{Heteroscedasticity Test and Robust Regression Analysis}

We conducted heteroscedasticity tests, both White test and BP test, for estimated model 1 and estimated model 2. In estimated model $1, p$-value is $0.24>0.05$ in White test, and in BP test the $p$-value is $0.17>0.05$. In estimated model 2 , with Lnyp (2015) as the explained variable, the results showed that $p$-value is $0.01<0.05$ in White test and $0.00<0.05$ in BP test. From the test above we find no evidence of heteroscedasticity in model 1 and that the OLS regression analysis is efficient. For the estimated model 2, we do find heteroscedasticity and that further robust regression analysis is needed.

The robust regression analysis also shows that BC and CC didn't promote enterprise' profits in 2015, and also the same to the year of 2012/2013/2014 we have tested. But the constraint of SH has negative relationship with profit achievement in 2015 which presents the same results in Table 6 . Negative regression coefficient of constraint of SH in 2015 is $p(2015)<0.05$, which means that it is statistically significant. So from the results of estimated model 1 and model 2, we can conclude that the agglomeration effects of Wuhan biopharmaceutical industry cluster, measured by network structural embeddedness dimensions of betweenness centrality, constraint of structure holes, and clustering coefficient in our paper, emerged directly and had positive effects on enterprises' innovation 
as represented by patents, while the agglomeration effects didn't facilitate significant effects on profits. In other words, the technological cooperation among the cluster have produced significant innovation achievements, in generating patents or other technological improvements, while not directly promoted enterprise's profits, which makes practical sense. Because technical cooperation is a long-term process and may take a long time to bring profits for enterprise and more importantly, enterprise's profits are mainly determined by the operation strategy and management methods of the company. We will analyze the cluster network in the following to better understand the overall cooperation status of the cluster. This is reported in Table 6.

Table 6. Regression analysis of structure embeddedness on economic performance.

\begin{tabular}{ccccc}
\hline VAR & Sub Model 5 & Sub Model 6 & Sub Model 7 & Model 2 \\
\hline SJ & $0.149^{* *}$ & 0.093 & 0.088 & 0.076 \\
& $(2.01)$ & $(1.55)$ & $(1.54)$ & $(1.28)$ \\
K & $0.33^{* *}$ & $0.356^{* * *}$ & $0.377^{* * *}$ & $0.406^{* * *}$ \\
& $(2.01)$ & $(2.66)$ & $(2.96)$ & $(3.03)$ \\
BC & 14.433 & 8.195 & 4.438 & 4.544 \\
& $(0.84)$ & $(0.59)$ & $(0.34)$ & $(0.33)$ \\
SH & $-6.773^{* *}$ & $-5.029^{* *}$ & $-6.436^{* * *}$ & $-6.444^{* * *}$ \\
& $(-2.08)$ & $(-1.9)$ & $(-2.56)$ & $(-2.43)$ \\
CC & $-44.758^{* *}$ & -33.973 & -30.204 & -29.567 \\
& $(-1.76)$ & $(-1.64)$ & $(-1.54)$ & $(-1.42)$ \\
N & 40 & 40 & 40 & 40 \\
F & $6.61^{* * *}$ & $6.98^{* * *}$ & $8.56^{* * *}$ & $7.91 * * *$ \\
Adj-R & 0.42 & 0.43 & 0.49 & 0.47 \\
\hline
\end{tabular}

Note: * Significance at the $p<0.1$ level; ${ }^{* *}$ Significance at the 0.05 level; ${ }^{* * *}$ Significance at the 0.01 level. S-M: submodel.

\subsection{Cluster Network Structure Analysis}

Betweenness centrality and clustering coefficient would produce positive impacts on innovation outputs based on regression analysis between structure embeddedness and patent outputs. Every one percent increase in strength of betweenness centrality and clustering coefficient would lead to an increase of $95.7 \%$ and $215.6 \%$, respectively, in innovation capability. This means paths are controlled by some core enterprises where information and resources are exchanged. However, positive effects are ameliorated due to the constraint of structure holes.

Subnetwork structures of the core industry cluster (Figures 2-4) are formulated to make comparative analysis that gives us an overall perspective on the industry cluster. Seventy-five universities, 41 research institutions, and 137 enterprises have established cooperative relationships with core enterprises respectively, which developed 124, 159, and 218 edges, respectively, in three different subnetwork structures.

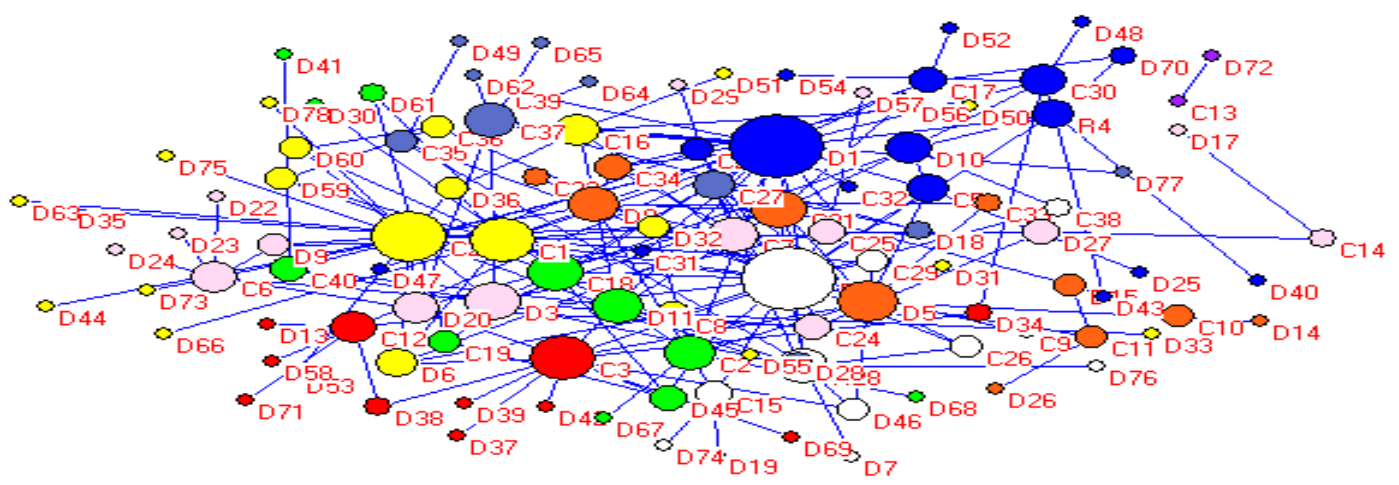

Figure 2. Network structure between core enterprises and universities. 


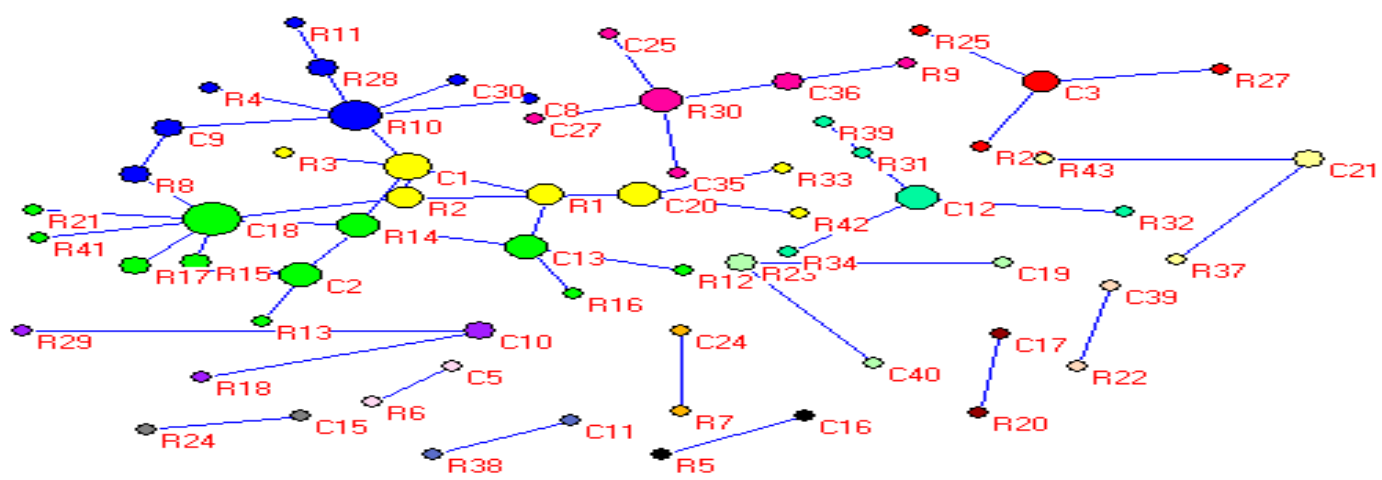

Figure 3. Network structure between core enterprises and research institutions.

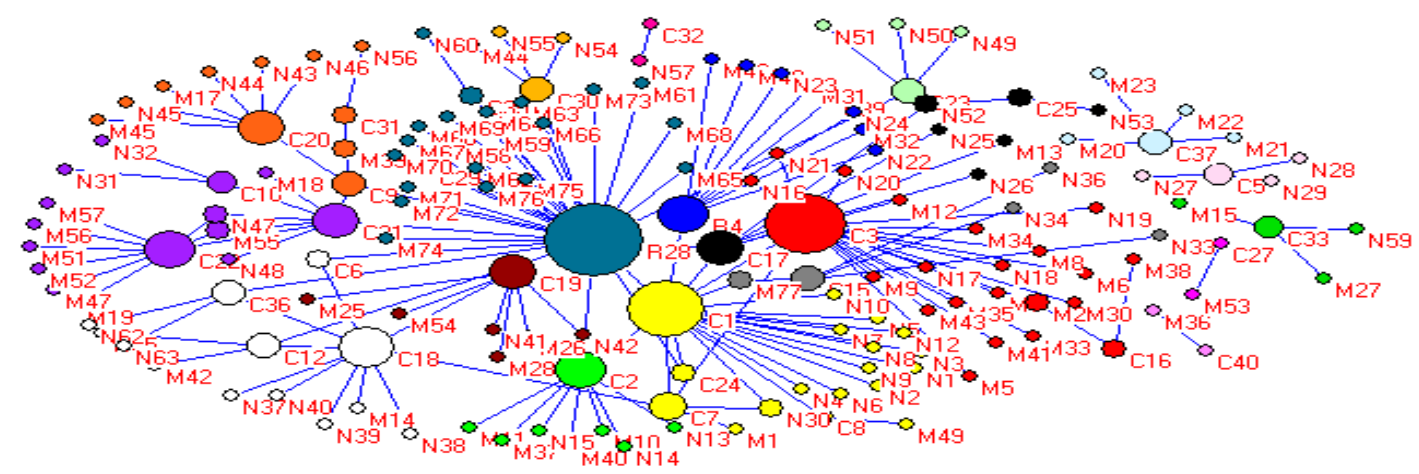

Figure 4. Network structure between core enterprises and other enterprises.

From Table 7, we can observe that interactive links among different actors are more close and intimate in subnetwork structure of core enterprises (40) and other enterprises (Figure 4), thus producing the largest average betweenness centrality and clustering coefficient (Figure 4) compared to overall subnetwork (Figures 2 and 3). E \& R, which represents network of enterprise and research institution (Figure 3), shows the relative low degree centrality of network and weak relationship between core enterprises and research institutions. Overall average clustering coefficient is smaller in both Figures 2 and 3, and cooperation between core enterprises and research institutions are loose as they are distributed in small groups. They are more likely to connect with research institutions in small groups or individually instead of being linked in large groups. This would not intensify the connection for the overall network in resource exchange. This has important implications for choosing technical cooperators. Because small group connections may benefit individuals as enterprises can maintain sustainable cooperation with lower cost. In Figure 4, interactive cooperation between enterprises is highly intensive, which indicates core enterprises enjoy a stronger relationship in the cluster network. These results are is reported in Tables 7-9.

Table 7. Robust regression analysis of structure embeddedness on economic performance.

\begin{tabular}{cccccc}
\hline Lnys(2015) & Coef. & Robust Std. Err.t & $\mathbf{t}$ & $\boldsymbol{p}>|\mathbf{t}|$ & \\
\cline { 1 - 4 } SJ & 0.077 & 0.045 & 1.67 & 0.103 & \\
K & 0.406 & 0.329 & 1.23 & 0.226 & Number of obs: 40 \\
BC & 4.544 & 14.054 & 0.32 & 0.748 & F $(5,34)=9.8$ \\
SH & -6.443 & 1.948 & -3.31 & $0.002 * * *$ & R-squared $=0.54$ \\
CC & -29.568 & 37.832 & -0.78 & 0.440 & \\
\hline
\end{tabular}

Note: ${ }^{*}$ Significance at the $p<0.1$ level; ${ }^{* *}$ Significance at the 0.05 level; ${ }^{* *}$ Significance at the 0.01 level. 
Table 8. Network Structure Features for Subgraphs.

\begin{tabular}{cccc}
\hline Network & DC & BC & CC \\
\hline C \& E (Figure 1) & 0.14 & 0.22 & 0.05 \\
E \& U (Figure 2) & 0.18 & 0.30 & 0.00 \\
E \& R (Figure 3) & 0.07 & 0.04 & 0.00 \\
E s\& E (Figure 4) & 0.17 & 0.45 & 0.02 \\
\hline
\end{tabular}

Note: DC: degree centrality of network; BC; and CC are the same as Table 2. C\&E: core enterprise and other three types of vectors: university, research institution, and other enterprises (Figure 1); E\&U: enterprise and university (Figure 2); E\&R: enterprise and research institution (Figure 3); and E\&E: enterprise other enterprises (Figure 4).

Table 9. Structure features of C1, C3, C20, D1, and D2 in Figure 2.

\begin{tabular}{ccccc}
\hline NAME & DC & BC & CC & SH \\
\hline C1 & 12 & 0.09 & 0.36 & 0.08 \\
C3 & 13 & 0.12 & 0.39 & 0.08 \\
C20 & 16 & 0.14 & 0.38 & 0.06 \\
D1 & 24 & 0.32 & 0.45 & 0.04 \\
D2 & 24 & 0.29 & 0.43 & 0.04 \\
\hline
\end{tabular}

Note: DC: degree centrality, CC: closeness centrality. Others are the same as Table 2.

Next, we focus on Figure 2, some enterprises and universities, for example, Humanwell Healthcare Group Co. Ltd. (C1), WuXi App Tec (C3), Ma yinglong Pharm (C20), Wuhan University (D1), and Huazhong University of Science and Technology (D2) possessed larger degree centrality, betweenness centrality and closeness centrality while smaller aggregate constraint of structure holes. This also contributes to a high degree centrality and betweenness centrality of network structure between enterprise and university (Figure 2).

Further, individual enterprise network structure graph is extracted from cluster network structure graph of core enterprises (40) for a micro-level analysis. In Figure 5, many SMEs have established relationship with $\mathrm{C} 1$ and $\mathrm{R} 28$ while they experience a lack of cooperation among themselves. This point has also been demonstrated in Figures 3 and 4. Therefore, C1 and R28 both control knowledge flow paths and act as intermediary actors. Financial and time costs have been spent in market transaction for SMEs. Therefore, a better business and policy environment is needed to ensure cooperation between SMEs.

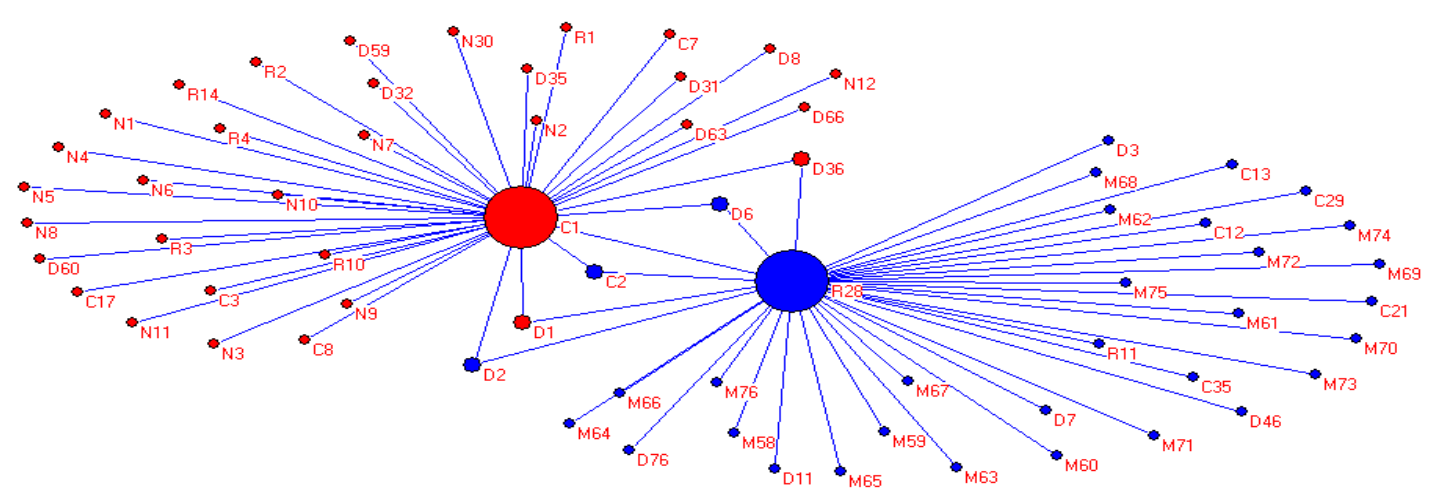

Figure 5. Network structure of C1 and R28.

\section{Discussion and Conclusions}

In this study, we examine whether technological spillover demonstrated by embeddedness have impacts on enterprises' outputs. We measured the degree of network structure embeddedness through collecting technological cooperation texts and calculating the scale of technological spillover with network analysis. Further, we have analyzed the characteristics of three different subnetworks. The results showed that with the fast development of biopharmaceutical industry in Wuhan East 
Lake High-Tech Zone, the positive spillover effects will become more prominent if more frequent and efficient cooperation developed not only among core enterprises, but also between SMEs and other types of network actors. The overall network structure can be optimized by strengthening intermediary function of core enterprises and institutions, by tightening exchanges among SMEs, and by removing constraint of core enterprises. The following suggestions may be helpful for decision makers both from the supply-side (government) and demand-side (enterprises) in promoting cluster development, and offer a reference for regions sharing similar conditions in rapid industrialization.

First of all, this article's findings confirm intermediary function of some core enterprises and research institutions in innovation diffusion. Wuhan, a central city in Central Region of China, with rich educational resources and research institutions, policy-makers (government) should encourage building multistakeholder technical service platforms, particularly resource integration and information transmission platforms, including Instruments Sharing Platform and Key Technology Service Platform. The involvement of enterprises in these platforms are essential.

Secondly, we learned from the analysis that cooperation among SMEs and SMEs with other types of network actors need to be strengthened. Regression analysis between structure embeddedness and economic performance demonstrated agglomeration effects on economic performance are not consistent with what we predicted. This suggests that policies should be provided to SMEs in the areas of capital, knowledge and technology and a better institutional environment is needed.

Finally, regression analysis between structure embeddedness and innovation outputs and economic performance demonstrated that aggregate constraint of structure holes generate negative impacts on core enterprises, and degree centrality play a limited role in improving outputs. This means core enterprises should decrease their redundant links with other actors. Policy-makers should slow down their efforts in supporting the "key controlled enterprise".

This study provides insights regarding paths for future research. First, future studies can collect data on innovation cluster from other regions in China, so that scholars are able to generate conclusions that are generalizable across geographic locations. Second, this study mainly used patents as the measure for innovation performance, future studies should also focus on more nuanced measurement of innovation performance.

Author Contributions: J.Z. contributes to the overall development of the idea, research design and writing of the article. D.L. contributes to the statistical analysis, literature review and initial draft. H.Y. contributes to theoretical framing, writing and revisions.

Funding: The authors acknowledge financial support from the youth fund project of the National Natural Science Foundation of China (Grant No: 71503268), the Fundamental Research Funds for the Central Universities from Zhongnan University of Economics and Law (Grant No: 2722019JCG061), Zhongnan University of Economics and Law Graduate Education Achievement Award Cultivation Project (Grant No: CGPY201904), Interdisciplinary Innovation Research Project (Grant No: 2722019JX002), and the National Social Science Foundation of China (Grant No: CFA150151).

Conflicts of Interest: The authors declare no conflict of interest.

\section{References}

1. Poter, M.E. Clusters and the New Economics of Competition. Harv. Bus. Rev. 1998, 98, 77-91.

2. Crafts, N.; Venables, A. Glohalization in History: A Geographical Perspective. In Globalization in Historical Perspective; University of Chicago Press: Chicago, IL, USA, 2001.

3. Caniëls, M.C.J.; Romijn, H.A. Firm-level knowledge accumulation and regional dynamics. Ind. Corp. Chang. 2003, 12, 1253-1278. [CrossRef]

4. Zaheer, A.; Bell, G.G. Benefiting from network position: firm capabilities, structural holes, and performance. Strat. Manag. J. 2005, 26, 809-825. [CrossRef]

5. Huggins, R.; Johnston, A. Knowledge Flow and Inter-firm Networks: The Influence of Network Resources, Spatial Proximity and Firm Size. Entrep. Reg. Dev. 2010, 22, 457-483. [CrossRef]

6. Seppänen, R.; Blomqvist, K.; Sundqvist, S. Measuring inter-organizational trust-A critical review of the empirical research in 1990-2003. Ind. Mark. Manag. 2007, 36, 249-265. [CrossRef] 
7. Tsai, W. Knowledge Transfer in Intraorganizational Networks: Effects of Network Position and Absorptive Capacity on Business Unit Innovation and Performance. Acad. Manag. J. 2001, 44, 996-1004.

8. Organisation for Economic Co-operation and Development (OECD). Innovative Clusters-Drivers of National Innovation Systems; OECD: Paris, France, 2001.

9. Melo, P.C.; Graham, D.J.; Noland, R.B. A meta-analysis of estimates of urban agglomeration economies. Reg. Sci. Urban Econ. 2009, 39, 332-342. [CrossRef]

10. Owen-Smith, J.; Powell, W.W. Knowledge Networks as Channels and Conduits: The Effects of Spillovers in the Boston Biotechnology Community. Organ. Sci. 2004, 15, 5-21. [CrossRef]

11. Powell, W.W.; Koput, K.W.; Smith-Doerr, L. Interorganizational collaboration and the locus of innovation: Network of learning in biotechnology. Adm. Sci. Q. 1996, 41, 116-145. [CrossRef]

12. Iammarino, S.; McCann, P. The structure and evolution of industrial clusters: Transactions, technology and knowledge spillovers. Res. Policy 2006, 35, 1018-1036. [CrossRef]

13. Tall-man, S.; Jenkins, M.; Henry, N.; Pinch, S. Knowledge, Cluster, and Competitive Advantage. Acad. Manag. Rev. 2004, 29, 258-271. [CrossRef]

14. Krätke, S. Network Analysis of Production Clusters: The Potsdam/Babelsberg Film Industry as an Example. Eur. Plan. Stud. 2002, 10, 27-54. [CrossRef]

15. Bell, G.G. Clusters, networks, and firm innovativeness. Strat. Manag. J. 2005, 26, 287-295. [CrossRef]

16. Wang, W. Does controllability of core enterprise in industrial innovation network will promote the spillover of knowledge. J. Manag. World 2015, 6, 101-109.

17. Chi, R. A study on node links of SMEs' innovation network in region and its effectiveness. J. Manag. World 2007, 1, 105-121.

18. Fan, Q. A study on structure embeddedness on cluster enterprises' innovation performance. J. Sci. Stud. 2010, 12, 1891-1900.

19. Ahuja, G. Collaboration networks, structural holes, and innovation: A logistical Study. Adm. Sci. Q. 2000, 45, 425-453. [CrossRef]

20. Qian, X. Firm Network Position, Indirect Ties, and Innovative Performance. China Ind. Econ. 2010, 2, 78-88.

21. Jiang, T. Network Site Technological Learning and Innovation Performance of Cluster Enterprises-Based on Empirical Study of Shaoxing Textile Industry Cluster. J. Econ. Geogr. 2012, 7, 87-106.

22. Caputo, F.; Livieri, B.; Venturelli, A. Intangibles and Value Creation in Network Agreements: analysis of Italian firms. Manag. Control. 2014, 45-70. [CrossRef]

23. De Bernardi, P.; Bertello, A.; Venuti, F. Online and On-Site Interactions within Alternative Food Networks: Sustainability Impact of Knowledge-Sharing Practices. Sustainability 2019, 11, 1457. [CrossRef]

24. Liu, X. Network Embeddedness, Knowledge Acquisition and Firms' Innovation Capabilities. J. Econ. Manag. 2015, 3, 150-159.

25. Veltri, S.; Venturelli, A.; Mastroleo, G. Measuring intellectual capital in a firm belonging to a strategic alliance. J. Intellect. Cap. 2015, 16, 174-198. [CrossRef]

26. Chen, W. Empirical Research on Innovation Networks Consisting of Industry-University-Research Institute in Regional Equipment Manufacturing Industry: A Perspective of Network Structure and Network Cluster. China Soft Sci. 2012, 2, 96-107.

27. Romano, A.; Passiante, G.; Elia, V. A Model of Connectivity for Regional Development in the Learning Economy. In Proceedings of the European Regional Science Association (40th) European Monetary Union and Regional Policy, Barcelona, Spain, 29 August-1 September 2000.

28. Gulati, R. Network location and learning: the influence of network resources and firm capabilities on alliance formation. Strat. Manag. J. 1999, 20, 397-420. [CrossRef]

29. Zahra, S.A.; Geogrge, G. Absorptive Capability: A Review, Reconceptualization and Extension. Acad. Manag. Rev. 2002, 27, 185-203. [CrossRef]

30. Uzzi, B. Social Structure and Competition in Interfirm Net-work: The Paradox of Embeddedness. Adm. Sci. Q. 1997, 42, 35-67. [CrossRef]

31. Dore, R. Goodwill and the Spirit of Market Capitalism. Br. J. Sociol. 1983, 34, 459-482. [CrossRef]

32. Romo, F.P.; Schwart, M. Structural Embeddededness of Business Decisions: A Sociological Assessment of Migration Behavior of Plants in New York State between 1960 and 1985. Am. Sociol. Rev. 1985, 60, 874-907. [CrossRef] 
33. Lee, T.W.; Mitchell, T.R.; Sablynski, C.J.; Burton, J.P.; Holtom, B.C. The Effects of Job Embeddedness on Organizational Citizenship, Job Performance, Volitional Absences, and Voluntary Turnover. Acad. Manag. J. 2004, 47, 711-722.

34. Zak, P.J.; Knack, S. Trust and Growth. Econ. J. 2001, 111, 295-321. [CrossRef]

35. Zeng, J.; Liu, T.; Feiock, R.; Li, F. The impacts of China's provincial energy policies on major air pollutants: A spatial econometric analysis. Energy Policy 2019, 132, 392-403. [CrossRef]

36. Schilling, M.A.; Phelps, C.C. Interfirm Collaboration Nerworks: The impact of Large-Scale Nerwork Structure on Firm Innovation. Manag. Sci. 2007, 53, 1113-1126. [CrossRef]

37. Burt, R.S. Structure Holes: The Social of Competition; Harvard University Press: Cambridge, MA, USA, 1992.

38. Watts, D.J. Networks, Dynamics, and the Small-World Phenomenon. Am. J. Sociol. 1999, 105, 493-527. [CrossRef]

(C) 2019 by the authors. Licensee MDPI, Basel, Switzerland. This article is an open access article distributed under the terms and conditions of the Creative Commons Attribution (CC BY) license (http://creativecommons.org/licenses/by/4.0/). 